\title{
Effect of Growth Techniques on the Structural, Optical and Electrical Properties of Indium doped $\mathrm{TiO}_{2}$ Thin Films
}

Faisal S. Al mashary a, b, *, Suelen de Castro ${ }^{\mathrm{c}}$, Arlon Fernando da Silva ${ }^{\mathrm{d}}$, Jorlandio Francisco Felix ${ }^{\mathrm{d}}$, Marcelo Rizzo Piton ${ }^{\mathrm{c}}$, Helder Vinícius Avanço Galeti ${ }^{\mathrm{c}}$, Ariano De Giovanni Rodrigues ${ }^{\mathrm{c}}$, Yara Galvão Gobato ${ }^{\mathrm{c}}$, Noor $\mathrm{Al}$ Saqri $^{\text {a }}$, Mohamed Henini ${ }^{\text {a, e }}$, Maryam M. Al huwayz ${ }^{\text {a }}$, Abdulrahman M. Albadri ${ }^{\mathrm{f}}$, Ahmed Y. Alyamani ${ }^{\mathrm{f}}$, Hamad A. Albrathen f, g, Sami A. Alhusaini ${ }^{\text {f }}$, Khalid M. Aljaber ${ }^{\text {f }}$, Ali Z. Alanazi ${ }^{\text {f }}$, Fahad S. Alghamdi ${ }^{\mathrm{f}}$

\footnotetext{
a School of Physics and Astronomy, University of Nottingham, Nottingham, NG7 2RD, United Kingdom

${ }^{\mathrm{b}}$ Department of Physics, College of Science, Qassim University, Buraydah, 14452, Saudi Arabia

${ }^{c}$ Departamento de Física, Universidade Federal de São Carlos, São Carlos 13560-905, Brazil

d Institute of Physics, Universidade de Brasília, Brasília, DF 70910-900, Brazil

${ }^{\mathrm{e}}$ UNESCO-UNISA Africa Chair in Nanoscience \& Nanotechnology Laboratories. College of Graduate Studies, University of South Africa (UNISA), Muckleneuk Ridge, PO Box 392, Pretoria, South Africa

${ }_{\mathrm{f}}^{\mathrm{f}}$ National Center for Nanotechnology and Advanced Materials, King Abdulaziz City for Science and Technology, Riyadh, 11442, Saudi Arabia

${ }^{g}$ Physics and Astronomy Department, ALASeR/KAIN, King Saud University, Riyadh 11451, Saudi Arabia

* Corresponding author. School of Physics and Astronomy, University of Nottingham, Nottingham, NG7 2RD, United Kingdom

E-mail address: faisal.almashary@ nottingham.ac.uk (F. S. Al mashary)
}

Keywords: In-doped TiO2, Pulsed laser deposition, Sputtering, XRD, Photoluminescence, Deep Level Transient Spectroscopy

\section{Abstract}

We have investigated the effect of the growth techniques on the structural, the electrically and optically active defects in Indium doped $\mathrm{TiO}_{2}$ thin films grown by pulsed laser deposition (PLD) and sputtering techniques. X-ray diffraction (XRD) and Raman spectroscopy patterns revealed both rutile and anatase phases for the sputtering samples. On the other hand, only the anatase phase was observed for the PLD samples. The photoluminescence (PL) spectra have unveiled several peaks which were explained by defect related optical transitions. Particularly, the PL bands are fully consistent with anatase/rutile $\mathrm{TiO}_{2}$ phases and the formation of $\operatorname{In}_{2} \mathrm{O}_{3}$ during the preparation of our samples. It was also observed that at $-4 \mathrm{~V}$ reverse bias, the PLD samples have lower leakage currents $\left(\sim 1.4 \times 10^{-7} \mathrm{~A}\right)$ as compared to the sputtering samples $\left(\sim 5.9 \times 10^{-7} \mathrm{~A}\right)$. In addition, the PLD samples exhibited lower ideality factors and higher barrier heights as compared to those grown by sputtering. Finally, the Deep Level 
Transient Spectroscopy (DLTS) measurements have shown only one defect in the PLD samples whereas five defects have been detected in the sputtering samples. Therefore, our results provide strong evidence that the PLD technique is better suited for the growth of In-doped $\mathrm{TiO}_{2}$ thin films.

\section{Introduction}

Transparent conducting oxides (TCOs) materials have wide applications in terms of absorbing, transparency of the visible light and electrical conductivity. They are used in optoelectronic, photovoltaic, photocatalytic and photoelectrochemical water splitting applications [1]. $\mathrm{TiO}_{2}$ is a $\mathrm{TCO}$ material which has been extensively studied for photocatalysis and photovoltaic applications. This wide interest in $\mathrm{TiO}_{2}$ is due to its efficient photoactivity, high stability, low cost and non-toxicity [2-4]. The large band gap (3.0-3.4 eV) [5,6] of $\mathrm{TiO}_{2}$ makes it only sensitive to UV light and therefore it is not efficient for solar cell applications. Among a lot of approaches that have been used to modify the electrical and optical properties of $\mathrm{TiO}_{2}$ in order to make it sensitive to visible light, metal ion doping has been proved to be one of the best methods [7]. Different metals have been used as dopants in $\mathrm{TiO}_{2}$ to change its electronic and optoelectronic properties [8]. Using indium as a dopant has attracted a lot of attention as it can modify some properties of $\mathrm{TiO}_{2}$, such as band gap, surface composition and charge transport.

Oxygen vacancies are well-known defects in $\mathrm{TiO}_{2}$ which can alter the geometric structure and the chemical properties of the system [9]. In addition to the defects that may be introduced into the forbidden band gap of $\mathrm{TiO}_{2}$ due to incorporating indium, the growth methods could also provide defect levels within the band gap. Understanding the deep and shallow level defects is essential for future devices [10]. Deep level transient spectroscopy (DLTS) and photoluminescence (PL) are powerful tools to investigate these defects in 
semiconductors. Particularly, by using DLTS, defects parameters such as the activation energy of a defect, its capture cross section and its concentration can be determined. In this study, we investigated the effect of growth techniques, namely pulsed laser deposition (PLD) and sputtering, on structural, optical and electrical properties of indium doped $\mathrm{TiO}_{2}$ thin films deposited on silicon substrates.

\section{Sample Details}

Two series of samples were prepared for this study using two different growth methods. For the first series, a layer of $380 \mathrm{~nm} \mathrm{TiO}_{2}$ thin film, measured using cross-section by scanning electron microscopy (SEM, HITACHI S4500), was deposited on (100) n-type silicon substrate using pulsed laser deposition (PLD/MBE 2100) from PVD products. The laser source was a $\mathrm{KrF}$ excimer Laser $(\lambda=248 \mathrm{~nm}$, pulse width $20 \mathrm{~ns}$, and repetition rate $=10 \mathrm{~Hz})$ operating at $350 \mathrm{~mJ}$ to ablate the target with two sets of pressure (under vacuum: $10^{-6}$ Torr and with oxygen background pressure: $5 \times 10^{-3}$ Torr). The growth temperature was fixed at $500{ }^{\circ} \mathrm{C}$ and the distance from substrate to target was set at $55 \mathrm{~mm}$. All PLD parameters which contribute to the growth rate were kept constant during the operating time. This series of samples is named PLD sample. In the second series, RF magnetron sputtering technique was used to deposit a $300 \mathrm{~nm}$ thin film of $\mathrm{TiO}_{2}$ on (100) n-type silicon substrate. This series is labelled as sputtering sample. For the RF sputtering system, the samples were deposited using a 2-inche $\mathrm{TiO}_{2}$ target at a temperature of $500{ }^{\circ} \mathrm{C}$ in pure Argon ambient without addition of oxygen. The chamber was evacuated to a high vacuum of less than $1 \times 10^{-8}$ Torr. The substrate was rotated during the deposition at a low speed to enhance the thickness uniformity of the films. Substrates were mounted on $300 \mathrm{~mm}$ stainless steel rotating disk where the distance between target and substrate was $150 \mathrm{~mm}$. High purity argon gas (99.999\%) was introduced at a rate of $22 \mathrm{sccm}$ as an inert gas for plasma. Before deposition, the samples were pre-sputtered in argon plasma 
for 10 mins to remove any contaminants. The working pressure was set to $10^{-3}$ Torr and RF power was fixed at $150 \mathrm{~W}$. By thermal evaporation, layers of indium (50 nm thick) were deposited on top of each sample set in order to keep the same doping concentration of indium and investigate only the effect of the growth techniques on the electrical and optical properties of In doped $\mathrm{TiO}_{2}$ thin films. In order to incorporate indium into the $\mathrm{TiO}_{2}$ lattice, both series of samples were annealed under oxygen flow with a temperature ramp rate of $15^{\circ} \mathrm{C} /$ minute and a dwelling temperature of $500{ }^{\circ} \mathrm{C}$ for 30 minutes. This annealing process has been found as the best among many annealing processes and procedures.

A third series of control samples, which do not contain In, were grown by sputtering and PLD techniques using the same procedures as described above. This will allow us to investigate the effect of In doping. These samples are labelled here as Reference samples

To prepare the samples for electrical characterization, the devices were processed in the form of circular mesas with a diameter of $900 \mu \mathrm{m}$. The back sides of the silicon substrates were exposed to evaporated Aluminium to create back ohmic contacts. Ti/Au has been deposited by thermal evaporation on top of the In-doped TiO2 layer to create Schottky contacts. Fig. 1 shows the growth and fabrication steps.

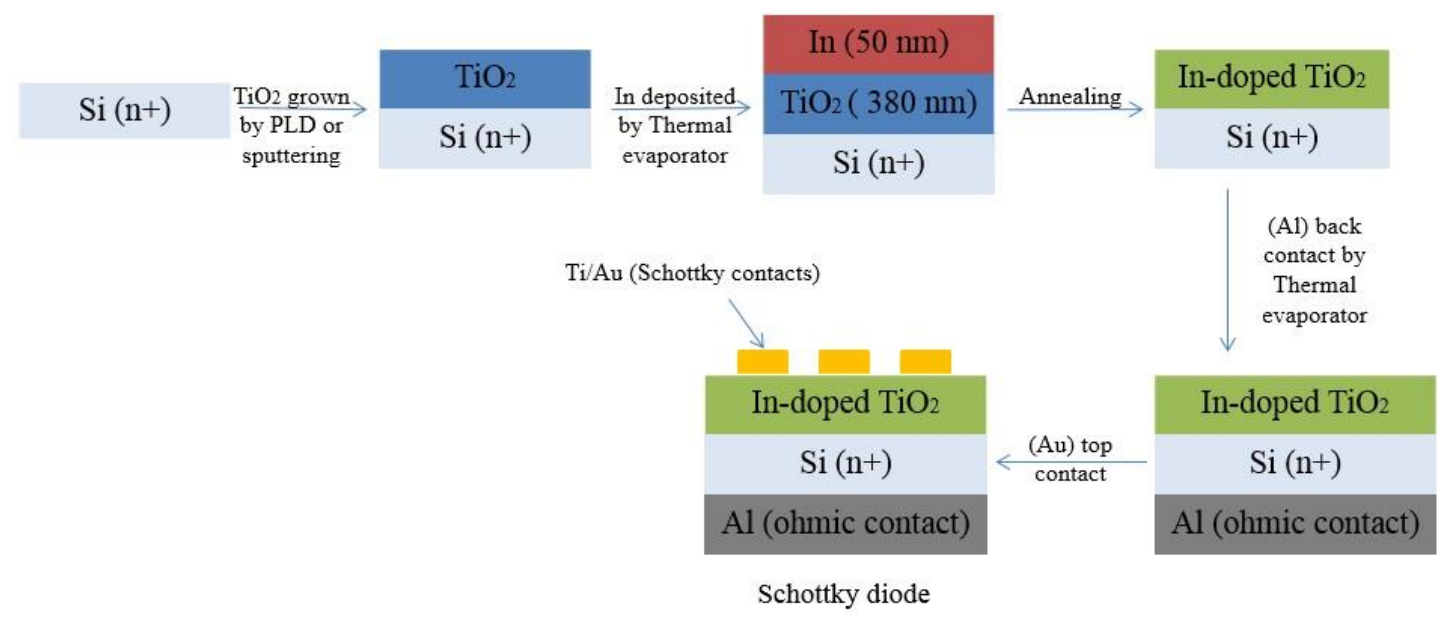

Fig. 1 Growth and fabrication steps. 
The photoluminescence (PL) spectra of In doped $\mathrm{TiO}_{2}$ thin films were investigated as a function of temperature using a laser excitation wavelength of $325 \mathrm{~nm}$. X-ray diffraction (XRD) patterns were measured in a Bruker D8 Discover Diffractometer, using $\mathrm{Cu} \mathrm{K} \alpha$ radiation $(\lambda=1.5418 \AA)$. The diffraction pattern was obtained at diffraction angles between $10^{\circ}$ and $80^{\circ}$ with geometry $2 \theta$ (the glancing angle X-ray diffraction-GAXRD method) and the conventional $\theta-2 \theta$ at room temperature. The Raman measurements were performed using a Renishaw micro Raman inVia spectrometer under ambient conditions. A laser with wavelength of $514 \mathrm{~nm}$ was used as an excitation source.

Current-voltage (I-V) measurements of both series of samples have been performed using a Keithley 236 source measure unit. Capacitance-voltage $(\mathrm{C}-\mathrm{V})$ measurements were investigated at $300 \mathrm{~K}$ with $1 \mathrm{MHz}$ frequency using Boonton 7200 capacitance meter. DLTS measurements were carried out using a He closed-loop cycle cryostat (Janis CCS-450) and Boonton 7200 capacitance meter.

\section{Results and Discussion}

\subsection{Structural and optical investigation}

Fig. 2 shows the XRD pattern of the PLD and sputtering samples. The XRD $\theta-2 \theta$ pattern of the sputtering reference sample (Fig. S1 in the supplement) exhibited diffraction peaks at $25.4^{\circ}$ and $25.5^{\circ}$ corresponding to the $(011)$ and (110) lattice planes revealing the anatase and rutile phases, respectively. Fig. 2(a) shows the XRD pattern of the In doped $\mathrm{TiO}_{2}$ sputtering sample (In doping obtained by depositing and annealing an indium layer of $50 \mathrm{~nm}$ thickness). The result shows the presence of anatase and rutile phases of $\mathrm{TiO}_{2}$, however, we can also notice 
an additional signature of indium oxide phase with the main peaks at $22.5^{\circ}, 30.6^{\circ}, 35.6^{\circ}, 47.3^{\circ}$, $51.1^{\circ}$, and $60.9^{\circ}$ corresponding to the (211), (222), (400), (431), (440), and (622) lattice planes of cubic $\mathrm{In}_{2} \mathrm{O}_{3}$ (JCPDS File no:06-0416), respectively. Additionally, the precipitation and formation of a second phase may contribute to the increasing of trap defects, as will be shown later using the DLTS technique. $\mathrm{TiO}_{2}$ thin film grown by sputtering technique composed of rutile and anatase phases have been also observed by Huang at al. [11].
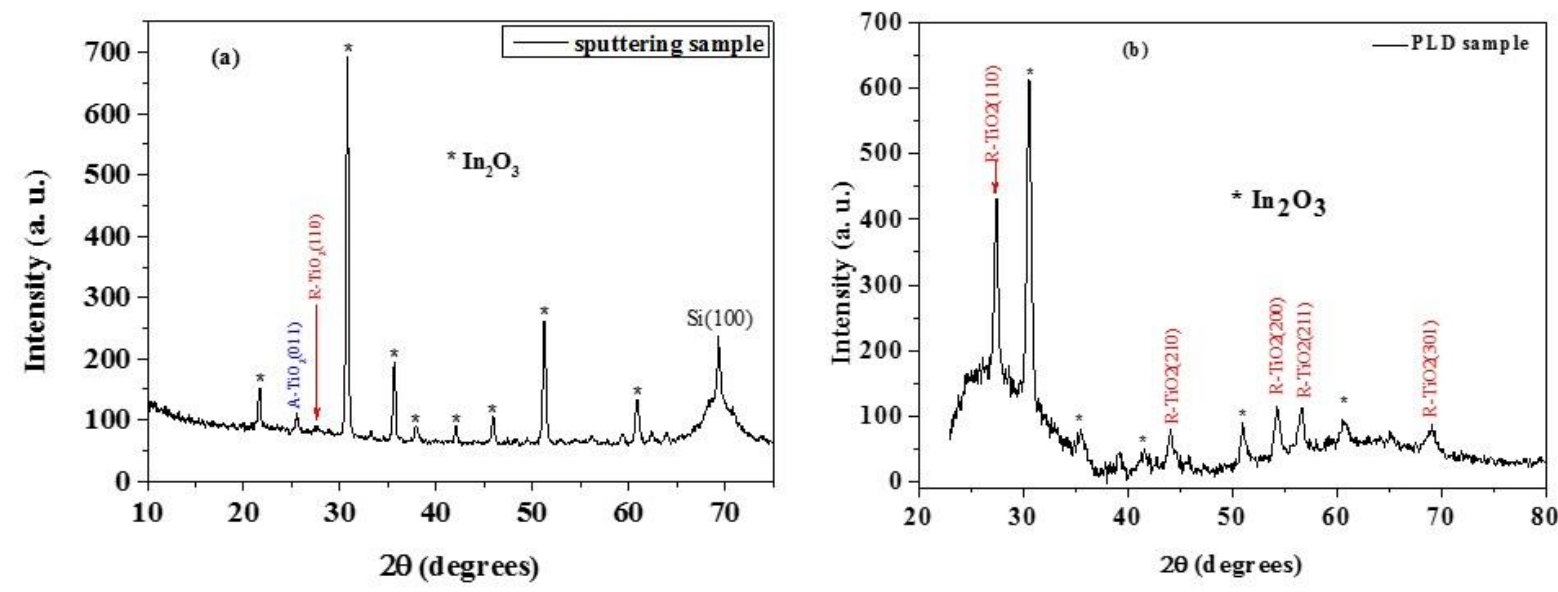

Fig. 2 Room temperature XRD pattern of In doped $\mathrm{TiO}_{2}$ thin films prepared by (a) sputtering and (b) PLD.

A single rutile phase characteristic of $\mathrm{TiO}_{2}$ thin films is obtained for PLD reference sample (Fig. S2 in the supplement). Fig. 2(b) shows the XRD pattern of PLD samples. The peaks are in good agreement with the standard XRD patterns of $\mathrm{TiO}_{2}$ found in the literature [11]. It can be seen that the peak $\mathrm{R}(110)$ strongly dominates over the other peaks related to rutile $\mathrm{TiO}_{2}$ structure, indicating the preferential orientation. However, in the In-doped $\mathrm{TiO}_{2} \mathrm{PLD}$ sample the presence of both indium oxide phase and $\mathrm{TiO}_{2}$ pure- rutile phase are observed (see Fig. 2(b)). From the XRD results, it is possible to conclude that for the sputtering reference sample both rutile and anatase phases are present, while only rutile phase was detected in PLD reference sample. Moreover, the presence of a layer of indium (50 nm thickness) causes the formation of $\operatorname{In}_{2} \mathrm{O}_{3}$ phases in both the sputtering and PLD samples. However, the polycrystalline character of the $\operatorname{In}_{2} \mathrm{O}_{3}$ phase is more intense in the sputtering samples. This 
latter behaviour will have a strong influence on the electrical properties of the devices, as will be shown later.

In order to confirm the XRD results, Raman studies have been performed. Fig. 3(a) shows the Raman spectra of the In-doped $\mathrm{TiO}_{2}$ samples obtained by sputtering, where both rutile and anatase phases are observed. The sputtering sample shows an intense peak at $\mathrm{E}_{\mathrm{g}}=142$ $\mathrm{cm}^{-1}$ from anatase phase. The inset of Fig. 3(a) shows a weak peak at $\mathrm{B}_{1 \mathrm{~g}}=399 \mathrm{~cm}^{-1}$ and $\mathrm{Eg}=638$ $\mathrm{cm}^{-1}$ that are characteristics of anatase phase of $\mathrm{TiO}_{2}$ [12]. A single band at $\mathrm{E}_{\mathrm{g}}=446 \mathrm{~cm}^{-1}$ from $\mathrm{TiO}_{2}$ rutile phase is also observed. Finally, a weak vibrational band has been observed for cubic $\mathrm{In}_{2} \mathrm{O}_{3}$ at $197 \mathrm{~cm}^{-1}$ which is assigned to the $\mathrm{O}-\mathrm{In}-\mathrm{O}$ bending modes of cubic $\operatorname{In}_{2} \mathrm{O}_{3}$. The most intense peaks at $520 \mathrm{~cm}^{-1}$ are due to the Raman signal from $\mathrm{Si}(100)$ substrates. The results from XRD also show similar behavior. The same Raman bands are also observed in the sputtering reference sample (Fig. S3 in the supplement).
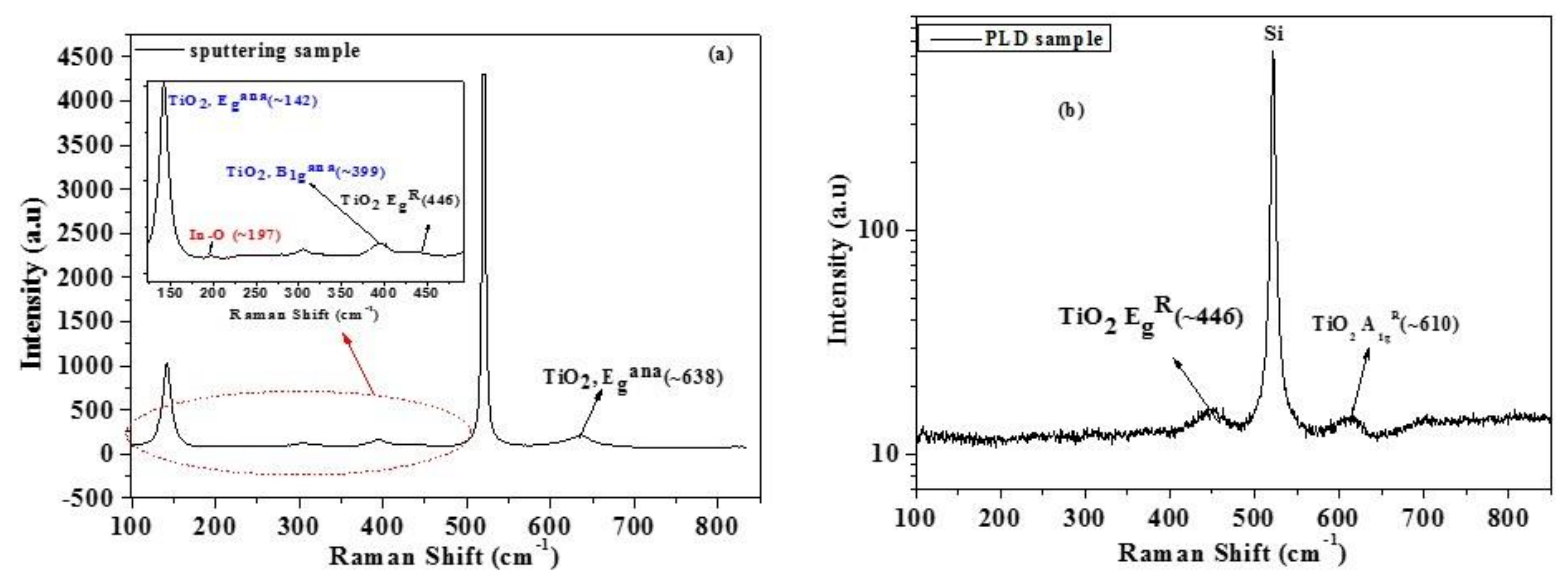

Fig. 3 Raman spectrum of In-doped $\mathrm{TiO}_{2}$ thin films prepared by (a) sputtering and (b) PLD.

Fig. 3(b) shows the Raman spectra of PLD samples. As can be seen in Fig. 3(b), only two peaks

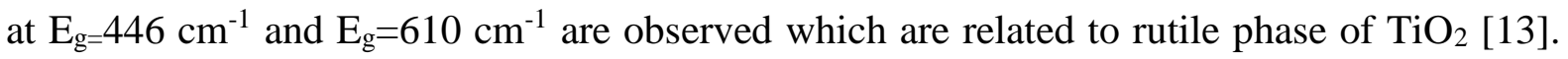
These results are in good agreements with XRD results, where only the rutile phase was 
observed. The Raman spectrum for PLD reference samples (Fig. S4 in the supplement) showed the same characteristics.

\subsection{Current-voltage measurements}

$\mathrm{I}-\mathrm{V}$ measurements as a function of temperature $(20-440 \mathrm{~K}$ with $20 \mathrm{~K}$ intervals) were performed in both samples in order to determine the diode parameters such as ideality factor $(n)$, barrier height $\left(\phi_{b}\right)$ and series resistance $\left(R_{s}\right)$. Fig. 4 shows the room temperature semilogarithmic plot of I-V characteristics for both samples. It can be seen from the figure that the reverse current of the sputtering sample is higher than that of PLD sample. In particular, the reverse bias leakage current at $-4 \mathrm{~V}$ for PLD and sputtering samples are $1.3 \times 10^{-7} \mathrm{~A}$ and 5.9 $\mathrm{x} 10^{-7} \mathrm{~A}$, respectively. This may indicate the presence of more defects in sputtering samples than PLD samples. These defects which act as generation-recombination centres and contribute to the tunnelling process in reverse bias can be probed by DLTS technique [8]. In addition, from the linear I-V plot (inset of Fig. 4) a turn-on voltage $\left(\mathrm{V}_{\text {on }}\right)$ of $0.26 \mathrm{~V}$ and $0.77 \mathrm{~V}$ was obtained for the sputtering and PLD sample, respectively.

The I-V characteristics of an ideal diode including series resistance $\left(R_{s}\right)$ could be described by the thermionic emission model [14] as:

$I=I_{0}\left[\exp \left(\frac{q(V-I R s)}{n K T}\right)-1\right]$

where $I_{0}$ is the saturation current and is given by:

$I_{0}=A A^{*} T^{2} \exp \left(\frac{-q \phi_{b}}{K T}\right)$

In Eqs. (1) and (2) $\mathrm{A}$ is the effective diode area $\left(A=6.362 \times 10^{-3} \mathrm{~cm}^{2}\right.$ for both samples), $A^{*}$ is the effective Richardson's constant $\left(A^{*}=671 \mathrm{~A} \mathrm{~cm}^{-2} \mathrm{~K}^{-2}[15]\right), k$ is Boltzmann's constant, $T$ is the temperature, $q$ is the elementary charge, $n$ is the ideality factor, $\phi_{b}$ is the barrier height and $R_{s}$ is the series resistance. In order to improve the accuracy of calculating the diode 
parameters $\left(n, \phi_{b}, R_{s}\right.$ and $\left.I_{0}\right)$, the Werner's method was used [16]. These parameters for PLD and sputtering samples at room temperature are shown in Table. 1.

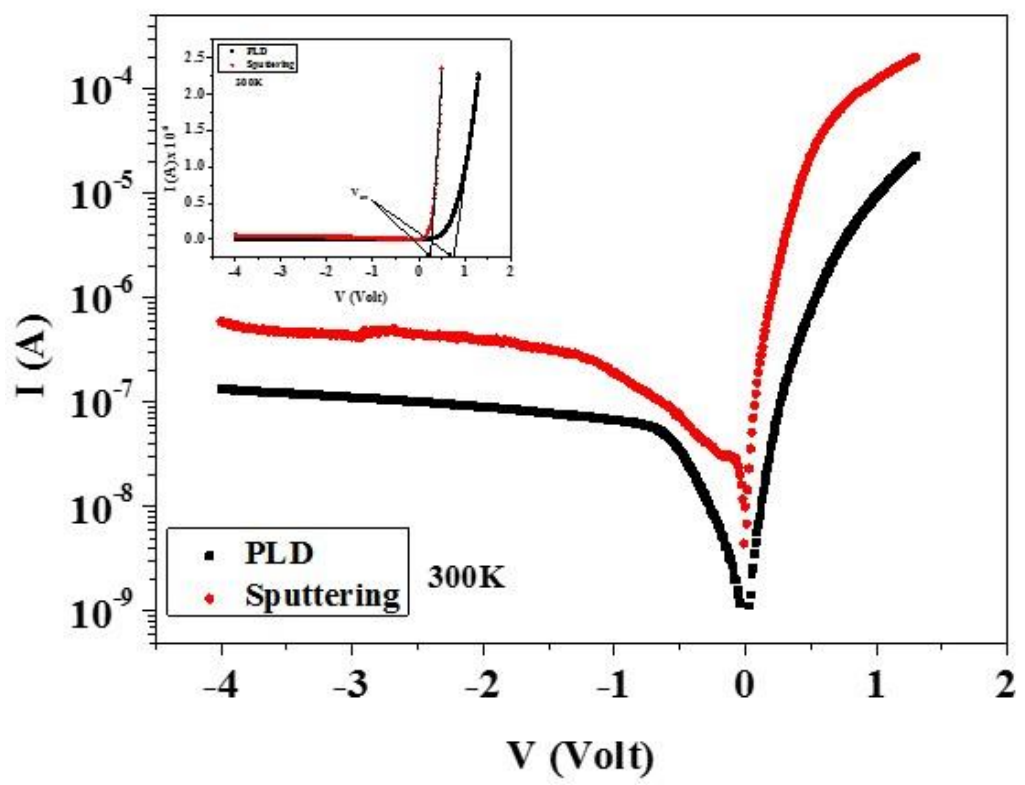

Fig. 4 Semi-logarithmic I-V plots for PLD and sputtering samples. The inset shows the linear I-V plot.

Table. 1 Ideality factor $(n)$, barrier height $\left(\phi_{b}\right)$ and series resistance $\left(R_{s}\right)$ at room temperature for PLD and sputtering samples.

\begin{tabular}{|c|c|c|c|}
\hline Sample & $n$ & $\phi_{B}(\mathrm{eV})$ & $R_{S}(\mathrm{k} \Omega)$ \\
\hline PLD & 2.01 & 0.87 & 330.86 \\
\hline sputtering & 2.54 & 0.77 & 5.92 \\
\hline
\end{tabular}

The plot of $\ln \left(\mathrm{I}_{0} / \mathrm{T}^{2}\right)$ versus 1000/T for PLD sample (Fig. S5 (a) in the supplement) in the temperature range 100-420 K follows a straight line. This behaviour suggests that the conduction mechanism could be governed by thermionic emission and the saturation current can be obtained using Eq. (2) [17]. A similar behaviour was observed in the sputtering sample in the temperature range 160-420 K (Fig. S5 (b) in the supplement). The Richardson constants that are calculated from the intercept of the straight line of $\ln \left(\mathrm{I}_{0} / \mathrm{T}^{2}\right)$ versus $1000 / \mathrm{T}$ plot for 
PLD sample $\left(\mathrm{A}^{*}=1.917 \times 10^{-6} \mathrm{~A} / \mathrm{K}^{2} \mathrm{~cm}^{2}\right)$ and sputtering sample $\left(\mathrm{A}^{*}=4.956 \times 10^{-8} \mathrm{~A} / \mathrm{K}^{2} \mathrm{~cm}^{2}\right)$ are much lower than the well-established value $\left(\mathrm{A}^{*}=671 \mathrm{~A} / \mathrm{K}^{2} \mathrm{~cm}^{2}\right)$. This deviation from the Richardson constant value may be due to the spatial inhomogeneous barrier and potential fluctuations at the interface that consist of low and high barrier areas [18, 19]. Fig. 5 shows the temperature dependence of the barrier height $\left(\phi_{B}\right)$ and ideality factor $(n)$ for both samples. As the temperature increases, the barrier height increases while the ideality factor decreases. This behaviour is known to be due to nonuniformity of interfacial charges. At low temperature, carriers are frozen and therefore the current does not follow the thermionic emission mechanism. At low temperatures, the current passes through the interface states and this result in higher values of the ideality factor [20]. Note that the carriers, at low temperature, can overcome the lower barriers and the mechanism of transport will be dominated by the current flowing through the region with lower barrier height. As temperature increases, carriers gain sufficient energy to overcome the higher barriers, which results in an increase of the barrier height with temperature [21].

The barrier height and ideality factor behaviour with temperature have been attributed to the barrier inhomogeneity. This inhomogeneity of barrier height was also confirmed by the almost linear relationship between barrier height and ideality factor for both samples (Fig. S6 in the supplement) [22]. It is worth noting that deviation from a linear relationship has been attributed to uncertainties in the calculation of the ideality factor [23]. 

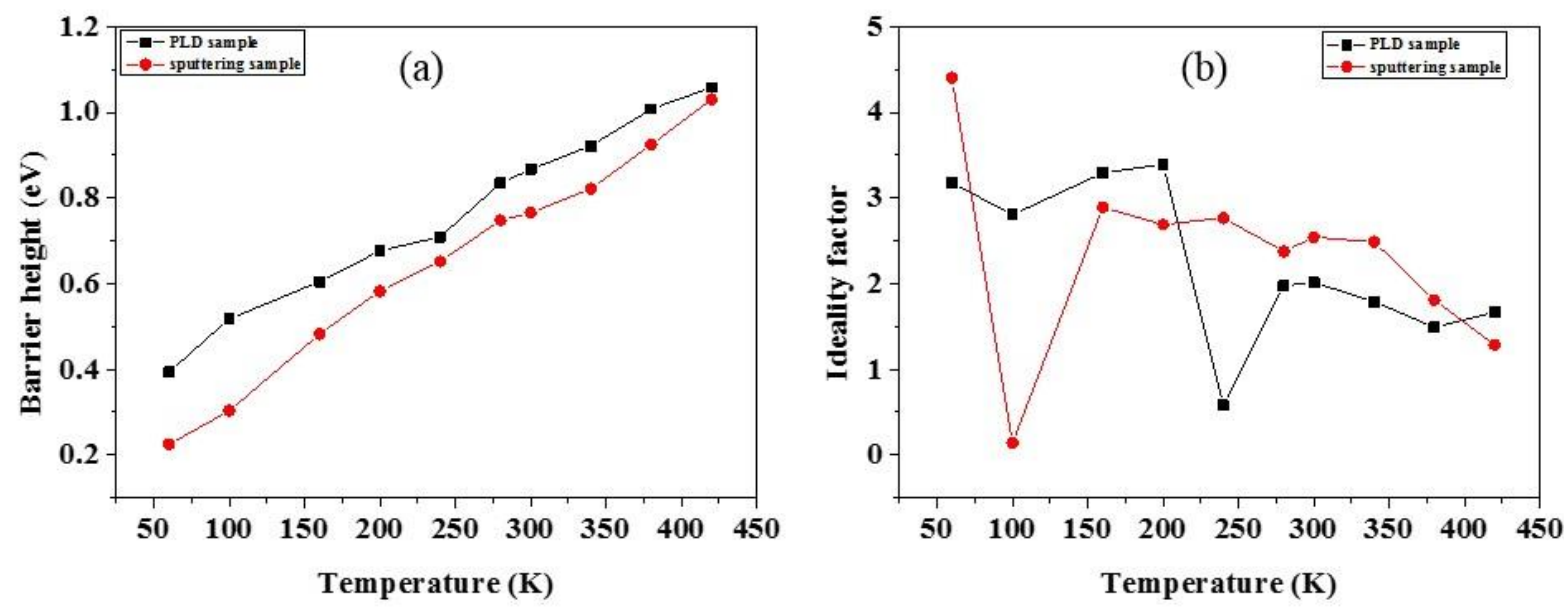

Fig. 5 In doped $\mathrm{TiO}_{2}$ samples grown by PLD and sputtering (a) barrier height $\left(\phi_{B}\right)$ versus temperature; (b) ideality factor $(n)$ versus temperature.

The main trap which contributes to the leakage current can be calculated using I-V measurements at different temperatures by plotting the reverse current versus inverse temperature [20]. Fig. 6 shows the plot of reverse current versus 1000/T for $-1 \mathrm{~V}$ bias voltage for both samples. One main trap has been found in PLD sample with an activation energy $E_{P L D}=0.492 \pm 0.007 \mathrm{eV}$. However, two traps have been detected in sputtering sample, namely $\mathrm{E}_{\mathrm{SP} 1}=0.100 \pm 0.005 \mathrm{eV}$ and $\mathrm{E}_{\mathrm{SP} 2}=0.51 \pm 0.04 \mathrm{eV}$. Note that $\mathrm{E}_{\mathrm{PLD}}$ and $\mathrm{E}_{\mathrm{SP} 2}$ have similar activation energies and the origin of this trap may be due to oxygen vacancy [7] or a deep donor $\mathrm{Ti}^{+3}$ state [10]. ESP1 may be related to oxygen vacancies or interstitial $\mathrm{Ti}$ ion [24]. A large number of defects determined from I-V measurements could be explained a high value of reverse current [20]. Since the sputtering sample has a larger number of defects than the PLD sample that could account of the larger value of the reverse current observed in the sputtering sample. It is worth noting that the numbers of traps found using the I-V measurements are consistent with those found by using optical technique, as we will show later. 


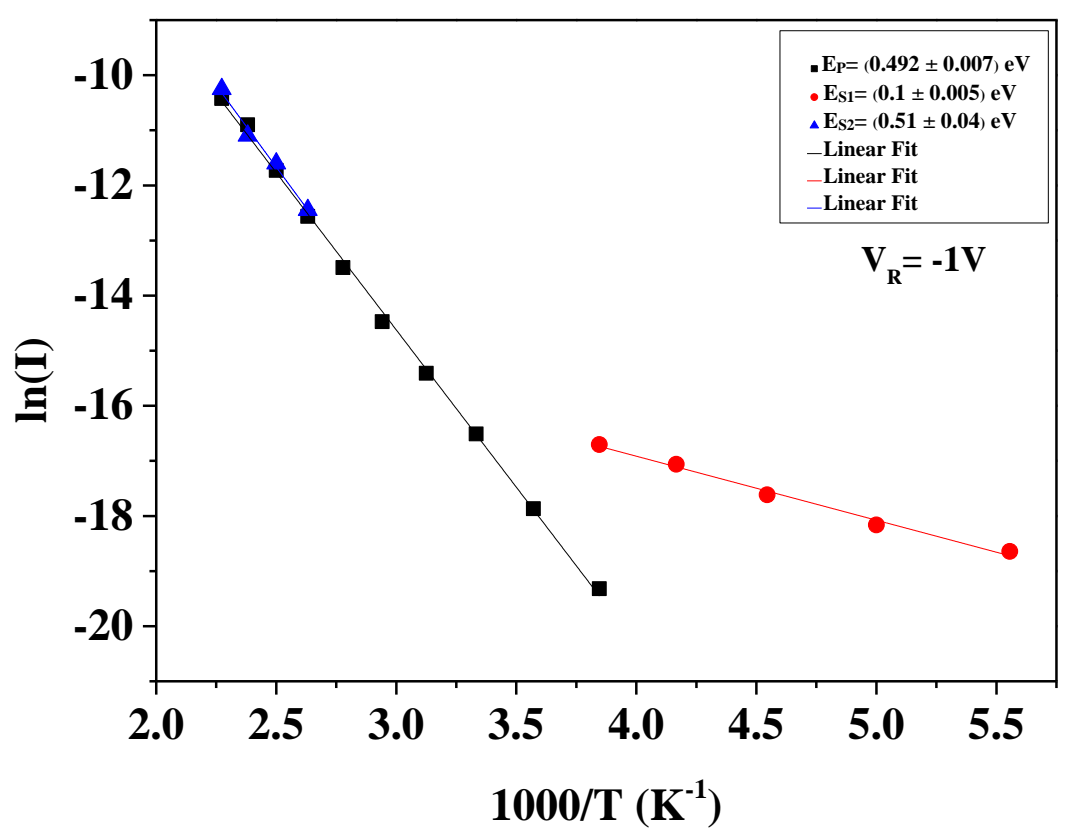

Fig. 6 Reverse current versus 1000/T for reverse bias voltage $\mathrm{V}_{\mathrm{R}}=-1 \mathrm{~V}$ for In-doped $\mathrm{TiO}_{2}$ samples prepared by PLD and sputtering

\subsection{Capacitance-voltage measurements}

The C-V measurements for both samples at room temperature are shown in Fig. 7(a). It is clear from the figure that the sputtering sample has higher capacitance than the PLD sample and this could be due to shallow ionised impurity levels. Also, a small shoulder can be seen in both samples, at $-0.6 \mathrm{~V}$ and at $-1.3 \mathrm{~V}$ for PLD and sputtering, respectively. This behaviour could be due to a poor interface quality and drift in carriers [8]. The slope of the best fit of the plot $1 / C^{2}$ versus reverse bias, Fig. 7(b), was used to calculate the free carrier concentrations, $N_{d}$, for both samples at room temperature. For the PLD sample, the doping concentration was found to be uniform as evidenced by the linear behaviour of the plot of $1 / \mathrm{C}^{2}$ versus applied bias. The free carrier concentration is about $5.4 \times 10^{13} \mathrm{~cm}^{-3}$. However, as depicted in Figure 7 (b), for the sputtering sample, two lines were fitted to the C-V data, confirming two different 
doping concentrations of $1.0 \times 10^{14} \mathrm{~cm}^{-3}$ and $\sim 3.0 \times 10^{14} \mathrm{~cm}^{-3}$. The free carrier concentration is higher near the junction interface than in the bulk.
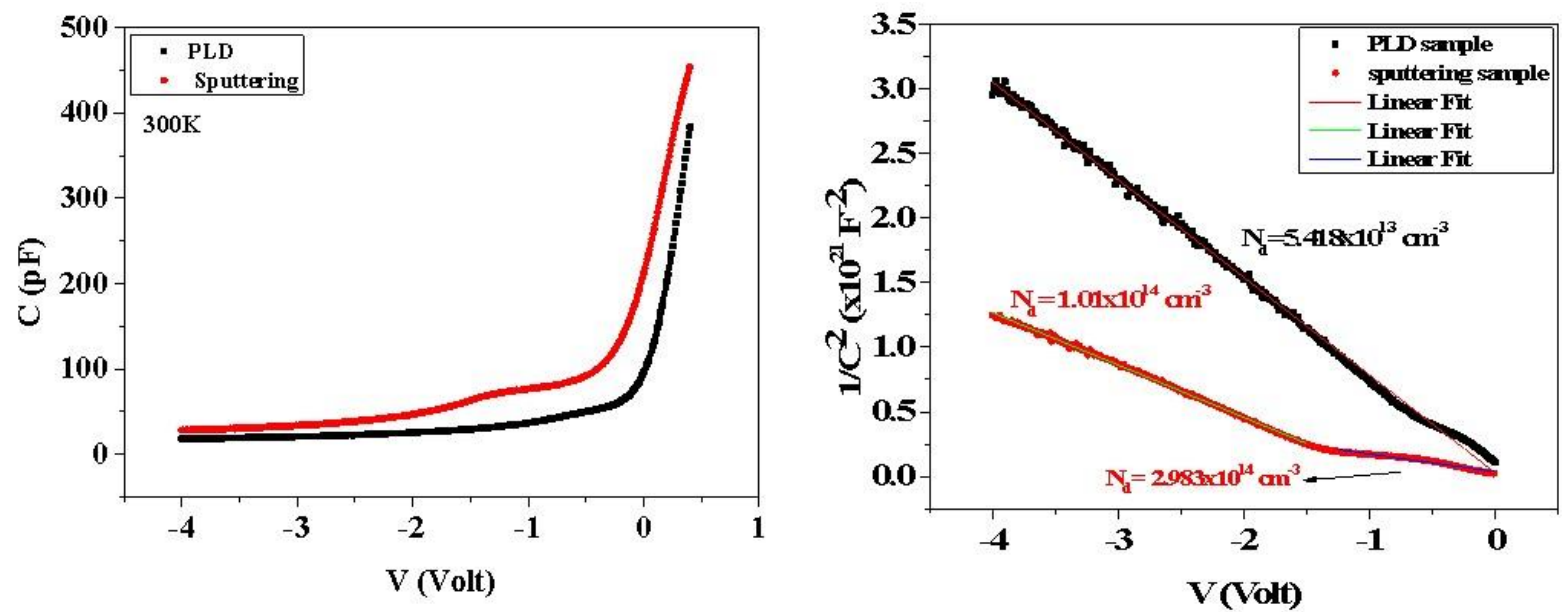

Fig. 7 (a) $\mathrm{C}-\mathrm{V}$ plot and (b) $1 / \mathrm{C}^{2}$ versus $\mathrm{V}$ plot at room temperature of In-doped $\mathrm{TiO} 2$ samples prepared by PLD and sputtering. 


\subsection{Optical properties}

Fig. 8 (a) and (b) show typical normalized PL spectra at 12K and 300K for both samples prepared by sputtering and PLD. It was observed that the PL spectrum of the sputtering sample consists of only one emission broad band around $1.95 \mathrm{eV}$. This result is similar to the one previously reported for In doped $\mathrm{TiO}_{2}$ films prepared by e-beam evaporation [8]. The nature of this emission band was previously attributed to the $\operatorname{~}^{3+}$ cation, which may produce a radiative transition between In (5P) and oxygen defect level [8]. However, the observed broad PL band could also be associated to optical transitions related to anatase and rutile phases. It can also include an important contribution of $\operatorname{In}_{2} \mathrm{O}_{3}$ which can be formed during the thermal annealing of the samples to incorporate In. On the other hand, the PLD sample has revealed several peaks. In order to understand the contribution of In doping we have also studied PL from reference samples prepared by sputtering and PLD. Fig. 8 (c) and (d) show the normalized PL spectra at $300 \mathrm{~K}$ for the reference and doped $\mathrm{TiO}_{2}$ samples prepared by both techniques. We remark that for the reference sample prepared by sputtering the PL spectra shows four emission peaks (Fig. 8(d)) at 300K. As will be discussed below, the anatase phase of $\mathrm{TiO}_{2}$ usually shows PL bands around 1.9 and $2.4 \mathrm{eV}$ while the rutile phase usually shows PL bands around 1.5 and $1.7 \mathrm{eV}$ [25]. Therefore, the PL peaks observed at $300 \mathrm{~K}$ for the reference sample prepared by sputtering are fully consistent with the presence of anatase and rutile phases which were also evidenced by XRD and Raman results.

As mentioned previously several bands were observed for the PLD sample in the visible and infrared region at $12 \mathrm{~K}$ and $300 \mathrm{~K}$ (Fig. 8(a) and $8(\mathrm{~b})$ ) which are labelled as $\mathrm{P}_{1}(1.93 \mathrm{eV})$, $\mathrm{P}_{2}(2.52 \mathrm{eV}), \mathrm{P}_{3}(2.90 \mathrm{eV})$, and $\mathrm{P}_{4}(3.25 \mathrm{eV})$ at $12 \mathrm{~K}$. In the following, we present a detailed discussion about the nature of these emission bands and possible interpretation of PL peaks observed in our PLD sample. 

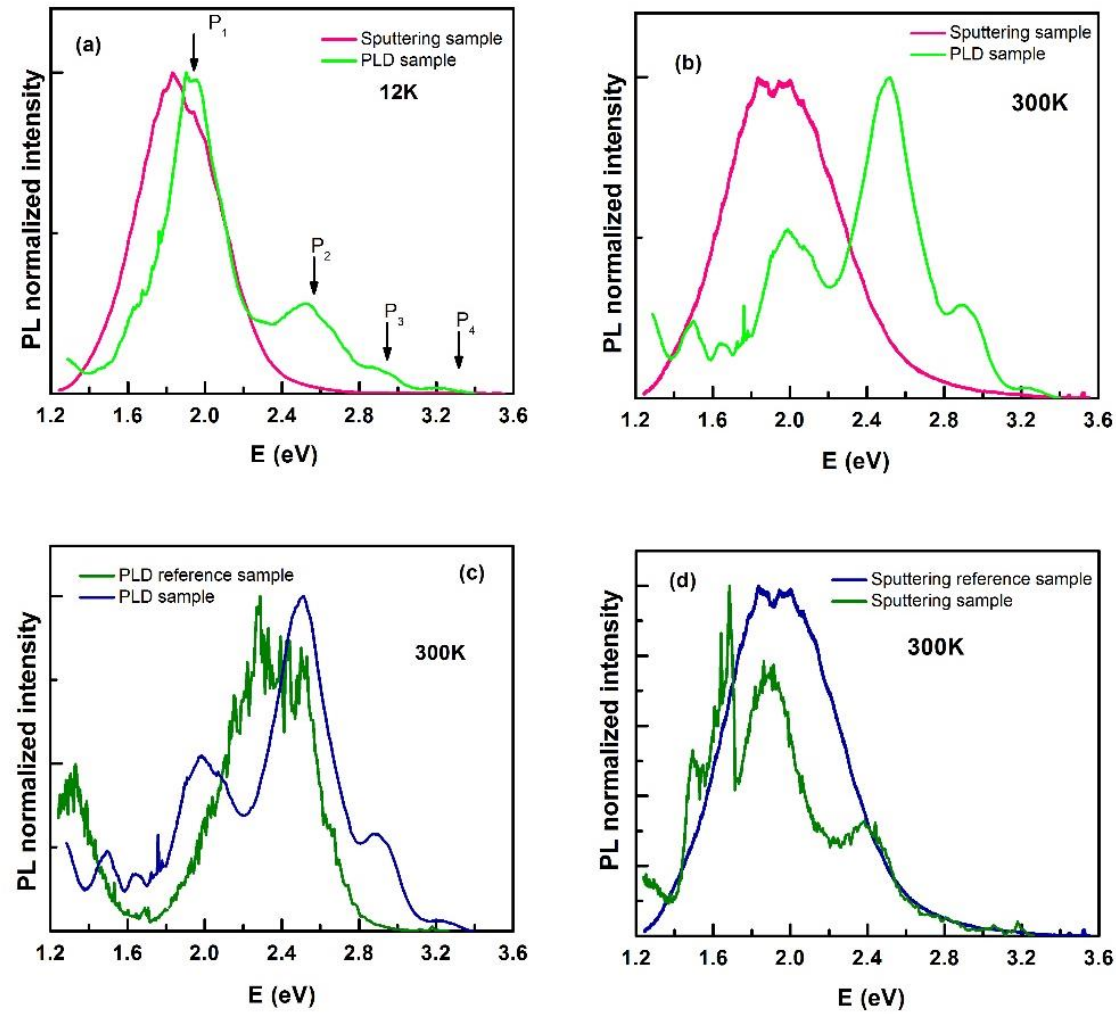

Fig. 8 Normalized PL spectra of In-doped $\mathrm{TiO}_{2}$ thin films grown by PLD and sputtering at (a) $12 \mathrm{~K}$ and (b) $300 \mathrm{~K}$. Comparison between PL emission at $300 \mathrm{~K}$ for undoped and $\mathrm{In}-$ doped $\mathrm{TiO}_{2}$ grown by (c) PLD and (d) sputtering.

As mentioned previously the PL spectra of $\mathrm{TiO}_{2}$ material usually depends on the crystal phase (anatase, rutile or mixed phases) [25]. It was reported [25] that the $\mathrm{TiO}_{2} \mathrm{PL}$ spectrum shows green (around $2.5 \mathrm{eV}$ ) and red (around $1.9 \mathrm{eV}$ ) emissions for the anatase phase and only a near-infrared emission (NIR) band around $1.5 \mathrm{eV}$ for the rutile phase. The green PL emission is usually attributed to self-trapped excitons [26], oxygen vacancies [27] and surface states [28]. However, a detailed study of these emissions has demonstrated that the green emission could also be related to radiative recombination of free electrons with trapped holes. These trapped holes could be localized at oxygen vacancies sites $\left(\mathrm{V}_{\mathrm{O}}\right)$ or at Ti sites adjacent to $\mathrm{V}_{\mathrm{O}}$ [25]. The red PL emission is usually related to recombination between trapped electrons and free holes [25]. On the other hand, the nature of NIR emission in $\mathrm{TiO}_{2}$ is more difficult to explain [25]. Usually, the rutile samples are less sensitive to prolonged exposure to UV 
illumination in oxygen environment than anatase samples, which suggests that the NIR PL could be associated to a possible radiative recombination between midgap trapped electrons and free holes at valence band. On the other hand, our XRD and Raman spectroscopy results have revealed both $\mathrm{TiO}_{2}$ and $\mathrm{In}_{2} \mathrm{O}_{3}$ phases for the In-doped $\mathrm{TiO}_{2}$ samples. The formation of $\mathrm{In}_{2} \mathrm{O}_{3}$ after the thermal annealing process which was used to incorporate $\mathrm{In}$ in the $\mathrm{TiO}_{2}$ lattice could also contribute to the PL bands observed in the In-doped $\mathrm{TiO}_{2}$ samples. It is well known that $\mathrm{In}_{2} \mathrm{O}_{3}$ oxide is also a wide band gap $(\sim 3.6 \mathrm{eV})$ semiconductor [29]. It was previously reported that the PL spectra displayed a near band edge (NBE) emission around $3.23 \mathrm{eV}$ and a defect-related emission at $\sim 1.98 \mathrm{eV}$ [30]. The PL peak in the visible region ( defect-related emission) was previously associated to the transition from the oxygen vacancy level to the valence band[31]. In addition, this red emission was also previously associated with deep level states $(1.94 \mathrm{eV})$ which can be present in $\mathrm{In}_{2} \mathrm{O}_{3}[32]$.

As mentioned above our In-doped $\mathrm{TiO}_{2}$ PLD samples revealed four emission bands (labelled $\mathrm{P}_{1}, \mathrm{P}_{2}, \mathrm{P}_{3}$ and $\mathrm{P}_{4}$ ). It was found that as the temperature increases, a gradual reduction of $\mathrm{P}_{1}$ emission band was observed as expected. However, additional weak emissions bands located around $1.5 \mathrm{eV}$ and $1.6 \mathrm{eV}$ were also detected. The PL peak energies of most of these bands are smaller than the energy gap of $\mathrm{TiO}_{2}$ and $\mathrm{In}_{2} \mathrm{O}_{3}$. Therefore, all these emission bands were attributed to the localized levels in the bandgap and could be due to intrinsic defects in both $\mathrm{TiO}_{2}$ and $\mathrm{In}_{2} \mathrm{O}_{3}$. As mentioned above, the observed defect emission peaks for $\mathrm{TiO}_{2}$ and $\mathrm{In}_{2} \mathrm{O}_{3}$ usually have emissions in the same energy range. Therefore, it is difficult to separate the contribution of defect-related emissions from the $\mathrm{In}_{2} \mathrm{O}_{3}$ and $\mathrm{TiO}_{2}$. In order to investigate which peak could be associated to the $\mathrm{TiO}_{2}$, we have also studied a reference sample, i.e. undoped $\mathrm{TiO}_{2}$ sample. Fig. 8 (c) shows the $300 \mathrm{~K}$ PL spectra of undoped and In-doped $\mathrm{TiO}_{2} 50 \mathrm{~nm}$ samples prepared by PLD. 
As can be seen in Fig. 8(c), the PL peaks of the undoped $\mathrm{TiO}_{2}$ thin film have a smaller intensity in the range of about $1.8-2.9 \mathrm{eV}$ and around $1.35 \mathrm{eV}$ as compared to those in In-doped $\mathrm{TiO}_{2}$ samples. The observed bands of $1.8-2.9 \mathrm{eV}$ and $\sim 1.35 \mathrm{eV}$ are assigned to the anatase and rutile phases (mixed phase), respectively [25]. The visible emission was associated to a combination of two bands previously reported in the literature for the anatase phase, namely the green band $(\sim 2.5 \mathrm{eV})$ and the red band $(\sim 1.9 \mathrm{eV})[25]$. However, the anatase phase was not evidence for XRD and Raman results. This band could be associated to small contribution anatase phase (mixed phase sample) that cannot be evidenced by XRD and Raman results but it is important for optical emission. On the other hand, emissions around 1.5 and $1.7 \mathrm{eV}$ have been observed only for the rutile phase and associated with the radiative recombination between midgap trapped electrons and free holes at the valence band [25] and $\mathrm{Ti}^{3+}$ ions [33]. We attribute the broad band around $1.2-1.6 \mathrm{eV}$ to the rutile phase. On the other hand, additional PL peaks $\left(\mathrm{P}_{1}, \mathrm{P}_{2}, \mathrm{P}_{3}\right.$ and $\left.\mathrm{P}_{4}\right)$ were observed in PLD sample which were associated to the formation of $\operatorname{In}_{2} \mathrm{O}_{3}$. Particularly, the $\mathrm{P}_{4}$ band that observed around $3.25 \mathrm{eV}$ at $12 \mathrm{~K}$ was associated to the band edge emission of $\operatorname{In}_{2} \mathrm{O}_{3}$ [32]. The other PL peaks $\left(\mathrm{P}_{1}, \mathrm{P}_{2}\right.$ and $\left.\mathrm{P}_{3}\right)$ have important contribution of defect emission due to $\operatorname{In}_{2} \mathrm{O}_{3}$. 
We have also investigated the temperature dependence of the emission bands for both PLD and sputtering samples. Figs. 9 (a) and (b) show a typical temperature dependence of PL spectra for these samples. It was found that the emission intensity of the peak at $1.93 \mathrm{eV}\left(\mathrm{P}_{1}\right)$ decreases considerably with the increase of temperature for both sputtering and PLD samples (please see Fig. 9(a)) as expected. However, the intensities of the other emissions of the PLD sample increase when the temperature increases (in the range of 100 to $300 \mathrm{~K}$ ). We believe that this effect could be associated to charge transfer, or traps due to the presence of defects or some disorder in $\mathrm{TiO}_{2}$ and/or $\mathrm{In}_{2} \mathrm{O}_{3}$. Traps could localize carriers non-radiatively, and the trapped carriers are thermally activated and contribute to the optically active states. We have also estimated the activation energy using a double-channel activation energies function $[34,35]$.

$I(T)=\frac{I_{0}}{1+\gamma_{1} \exp \left(-E_{a 1} /\left(k_{B} T\right)\right)+\gamma_{2} \exp \left(-E_{a 2} /\left(k_{B} T\right)\right)}$

where $I_{o}$ is the PL intensity at $T=0 \mathrm{~K}, \gamma_{1,2}$ are two constants related to the ratio between radiative and non-radiative recombination processes, $E_{a 1,2}$ are the activation energies corresponding to the non-radiative recombination process, and $k_{B}$ is the Boltzmann constant. 
The inset in Fig. 9(a) and (b) shows the temperature $\left(1 / k_{\mathrm{B}} T\right)$ dependence of the integrated PL intensity $(I)$ (Arrhenius plot) in the temperature range $T=12-300 \mathrm{~K}$ for PLD sample $\left(\mathrm{P}_{1}=1.93\right.$ $\mathrm{eV}$ ) and sputtering sample (peak at $1.95 \mathrm{eV}$ ). Clearly, the emission intensity decreases with increasing temperature following an Arrhenius-like function. Equation (3) has been used to fit the PL intensity in the whole measured temperature range (dash line). Activation energies of $E_{S P a 1}=82.0 \mathrm{meV}$ and $E_{S P a 2}=12.0 \mathrm{meV}$, and $E_{P L D a 1}=22.3 \mathrm{meV}$ were obtained for sputtering and PLD thin films, respectively. Al Saqri et al. [8] reported a defect in In-doped $\mathrm{TiO}_{2}$ thin films with an activation energy of $62 \mathrm{meV}$. They attributed this defect to the intrinsic Ti atoms and ionization energies of oxygen vacancies. In our case, the calculated activation energy could also be related to the similar nature which has already been evidenced from emission processes.
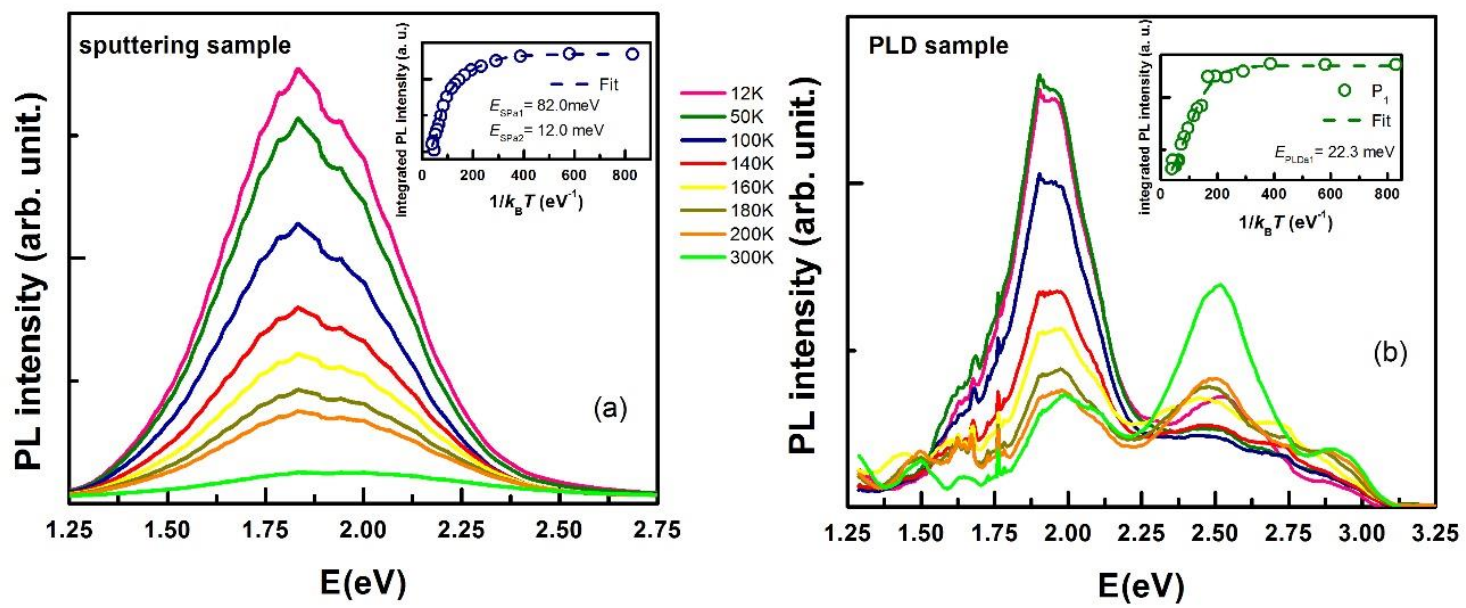

Fig. 9 PL spectra of (a) sputtering sample and (b) PLD sample at different temperatures in the range $12-300 \mathrm{~K}$. The insert shows the Arrhenius plot of total intensity for both samples. 
In conclusion, we have observed well resolved PL bands in the PLD sample and a broad PL band in the sputtering sample. These results provide strong evidence that PLD samples are of higher quality than sputtering samples. However, important contribution defect emission from the formation of $\operatorname{In}_{2} \mathrm{O}_{3}$ was observed in the PL from PLD samples. These results are also consistent with the I-V results for PLD samples which have shown better performance than the sputtering samples. The optical results are also consistent with the DLTS results which will be presented below.

\subsection{DLTS and Laplace DLTS measurements}

In order to investigate the effect of the growth techniques on the electrically active defects, DLTS technique has been used [36]. The experiment was carried out with a reverse bias, $V_{R}=-1 \mathrm{~V}$, filling pulse height, $V_{P}=0 \mathrm{~V}$, filling pulse time, $t_{P}=1 \mathrm{msec}$ and rate windows $200 \mathrm{~s}^{-1}$ for both samples. Fig. 10 shows the DLTS signals versus temperature for both samples over the scanned temperature range $10 \mathrm{~K}-450 \mathrm{~K}$. Broad peaks due to electron traps have been detected in both samples as shown in Fig. 10. Laplace DLTS measurements [37] have been carried out on both samples in order to resolve the broader peaks. In the Laplace DLTS spectra (Fig. S7 in the supplement) only one electron trap $\left(\mathrm{E}_{\mathrm{P}}\right)$ and five electron traps $\left(\mathrm{E}_{\mathrm{s} 1}, \mathrm{E}_{\mathrm{s} 2}, \mathrm{E}_{\mathrm{s} 3}, \mathrm{E}_{\mathrm{s} 4}\right.$, and $E_{\mathrm{s} 5}$ ) were detected in the PLD and sputtering samples, respectively. The activation energies of these traps were calculated from the Arrhenius plots as shown in Fig. 11. The trap parameters, such as activation energies, trap concentrations and capture cross sections are summarised in Table.2.

As seen in Table. 2, traps $E_{p}$ and $E_{s 4}$ have the same energies so they may have the same origin which could be assigned to oxygen vacancy as reported by E. Wang et al. [7] in In-doped $\mathrm{TiO}_{2}$ doped using the sol-gel method. However, B. Morgan and G. Watson have investigated the formation of native defects in anatase $\mathrm{TiO}_{2}$ using the density functional theory [10] and 
assigned a trap at $0.5 \mathrm{eV}$ to $\mathrm{Ti}^{+3}$ state. $\mathrm{E}_{\mathrm{p}}$ and $\mathrm{E}_{\mathrm{s} 4}$ could have the same origin. $\mathrm{E}_{\mathrm{s} 1}$ is a shallow level trap and $\mathrm{E}_{\mathrm{s} 2}$ may be related to oxygen vacancy or interstitial Ti ion [24]. The $\mathrm{E}_{\mathrm{s} 2}$ trap was also observed using PL measurement, labeled as $E_{S P a 1} . \mathrm{E}_{\mathrm{s} 3}$ and $\mathrm{E}_{\mathrm{s} 5}$ may be assigned to a $\mathrm{Ti}$ donor level [38].

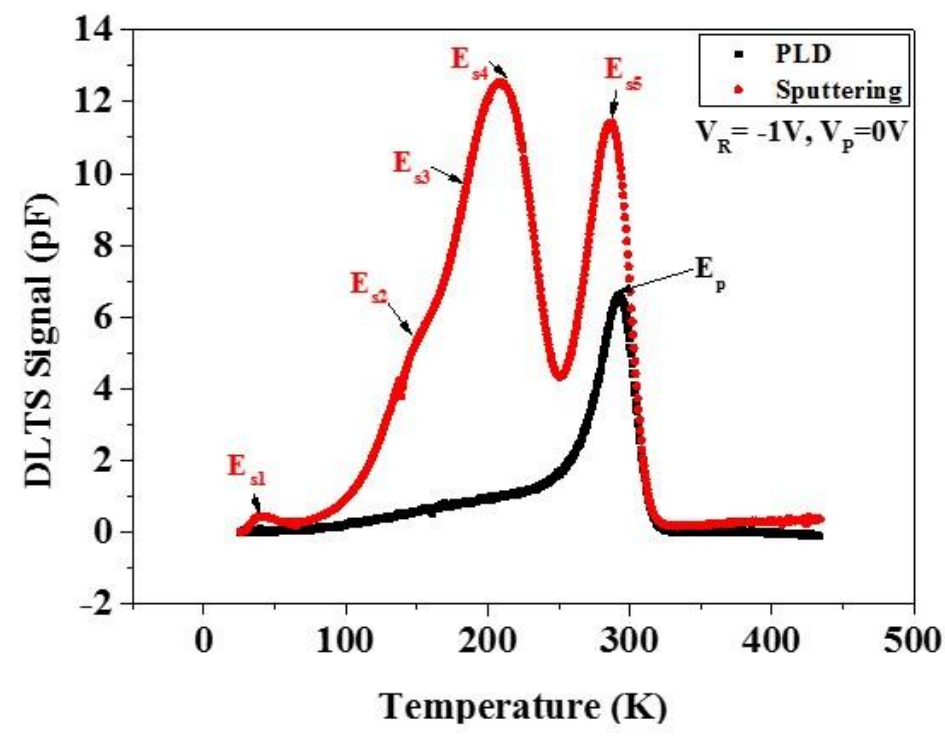

Fig. 10 DLTS signal for PLD and sputtering samples.
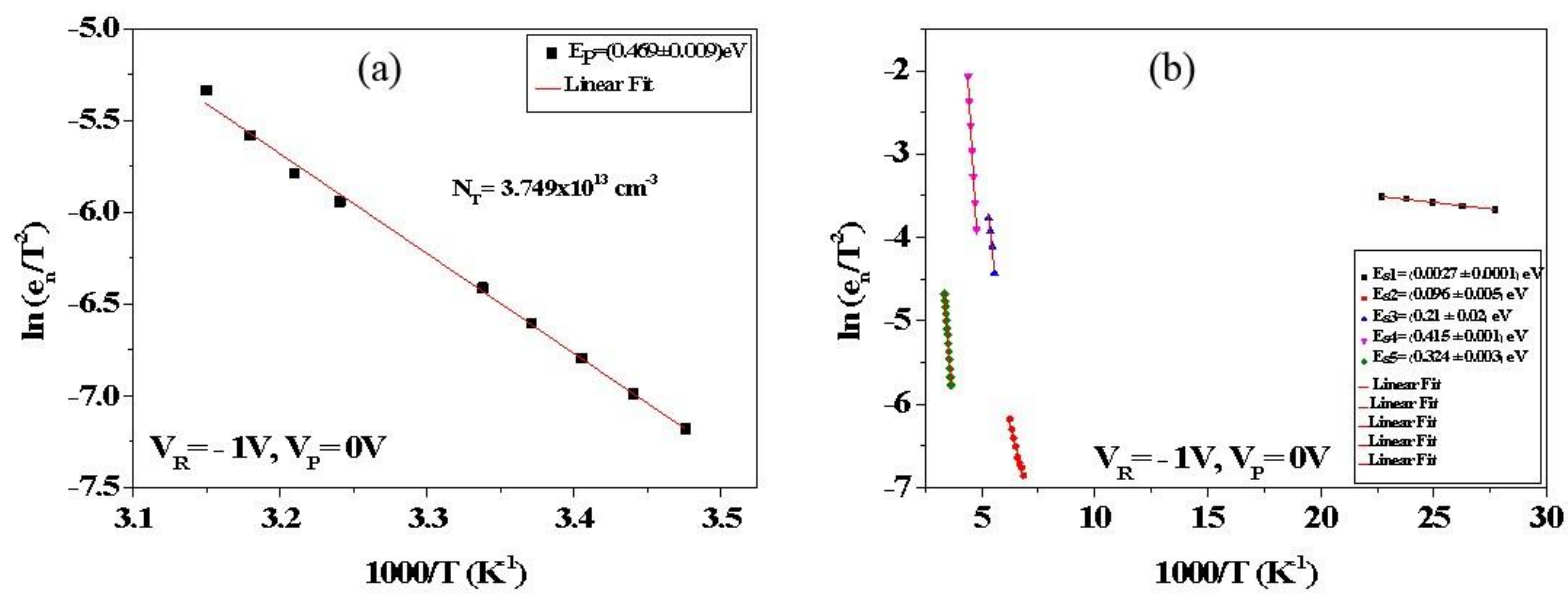

Fig. 11 Arrhenius plots from Laplace DLTS with reverse biases, $V_{R}=-1 \mathrm{~V}$, filling pulse height, $V_{P}=$ $0 \mathrm{~V}$, and filling pulse time, $\mathrm{t}_{\mathrm{P}}=1 \mathrm{msec}$, for (a) PLD sample and (b) sputtering sample 
Table. 2 Traps parameters for PLD and sputtering samples at $V_{R}=-1 V, V_{P}=0 V$ and $t_{P}=1 \mathrm{msec}$.

\begin{tabular}{|c|c|c|c|c|}
\hline Sample & Trap & $\begin{array}{c}\text { Activation } \\
\text { Energy } \\
(\mathrm{eV})\end{array}$ & $\begin{array}{c}\text { Capture Cross- } \\
\text { Section }\left(\sigma_{\infty}\right) \\
\left(\mathrm{cm}^{2}\right)\end{array}$ & $\begin{array}{c}\text { Trap Concentration } \\
\left(\mathrm{cm}^{-3}\right)\end{array}$ \\
\hline \multirow{6}{*}{ PLD } & $\mathrm{E}_{\mathrm{p}}$ & $0.469 \pm 0.009$ & $3.998 \times 10^{-16}$ & $3.749 \times 10^{13}$ \\
\hline \multirow{5}{*}{ sputtering } & $\mathrm{E}_{\mathrm{s} 1}$ & $0.0027 \pm 0.0001$ & $1.958 \times 10^{-22}$ & $5.027 \times 10^{12}$ \\
\cline { 2 - 5 } & $\mathrm{E}_{\mathrm{s} 2}$ & $0.096 \pm 0.005$ & $6.629 \times 10^{-21}$ & $3.939 \times 10^{13}$ \\
\cline { 2 - 5 } & $\mathrm{E}_{\mathrm{s} 3}$ & $0.21 \pm 0.02$ & $4.013 \times 10^{-17}$ & $9.187 \times 10^{13}$ \\
\cline { 2 - 5 } & $\mathrm{E}_{\mathrm{s} 4}$ & $0.415 \pm 0.001$ & $5.919 \times 10^{-13}$ & $1.585 \times 10^{14}$ \\
\cline { 2 - 5 } & $\mathrm{E}_{\mathrm{s} 5}$ & $0.324 \pm 0.003$ & $8.975 \times 10^{-18}$ & $1.341 \times 10^{14}$ \\
\hline
\end{tabular}

DLTS measurements using different reverse biases are usually performed to control the depletion region width (moving it away or close to the interface) where the process of trapping and de-trapping of carriers happen. DLTS measurements have been carried out for PLD sample at different reverse biases $V_{R}=-1,-3$, and $-4 \mathrm{~V}$, as shown in Fig. 12. The filling pulse height, $V_{P}=0 \mathrm{~V}$ and the filling pulse time, $t_{P}=1 \mathrm{msec}$, were kept the same for all measurements. As we change the reverse bias $V_{R}$, only one trap has been detected for each reverse bias. Table 3 shows the trap parameters for $V_{R}=-1,-3$ and $-4 \mathrm{~V}$. Arrhenius plots for $V_{R}=-3$ and $-4 \mathrm{~V}$ are displayed in Fig. 13. The trap found at $V_{R}=-3 \mathrm{~V}$ has the same activation energy as that at $V_{R}=$ $-4 \mathrm{~V}$ whose origin could be related to the Ti donor [38]. Note that the amplitude of the DLTS signal is decreasing as the reverse bias increases (away from the interface). This means that the concentration of the trap is decreasing as moving away from the interface. 
Table. 3 Traps parameters for PLD sample at $\mathrm{VR}=(-1,-3$ and -4$) \mathrm{V}, \mathrm{VP}=0 \mathrm{~V}$ and $\mathrm{t}_{\mathrm{P}}=1$ msec.

\begin{tabular}{|c|c|c|c|c|}
\hline $\begin{array}{c}\text { Reverse bias } \\
(\mathrm{V})\end{array}$ & Trap & $\begin{array}{c}\text { Activation Energy } \\
(\mathrm{eV})\end{array}$ & $\begin{array}{c}\text { Capture Cross- } \\
\text { Section }\left(\sigma_{\infty}\right) \\
\left(\mathrm{cm}^{2}\right)\end{array}$ & $\begin{array}{c}\text { Trap } \\
\text { Concentration } \\
\left(\mathrm{cm}^{-3}\right)\end{array}$ \\
\hline-1 & $\mathrm{E}_{\mathrm{p}}$ & $0.469 \pm 0.009$ & $3.998 \times 10^{-16}$ & $3.749 \times 10^{13}$ \\
\hline-3 & $\mathrm{E}_{\mathrm{p} 1}$ & $0.335 \pm 0.003$ & $1.171 \times 10^{-17}$ & $2.854 \times 10^{13}$ \\
\hline-4 & $\mathrm{E}_{\mathrm{p} 1}$ & $0.318 \pm 0.002$ & $7.779 \times 10^{-18}$ & $2.101 \times 10^{13}$ \\
\hline
\end{tabular}

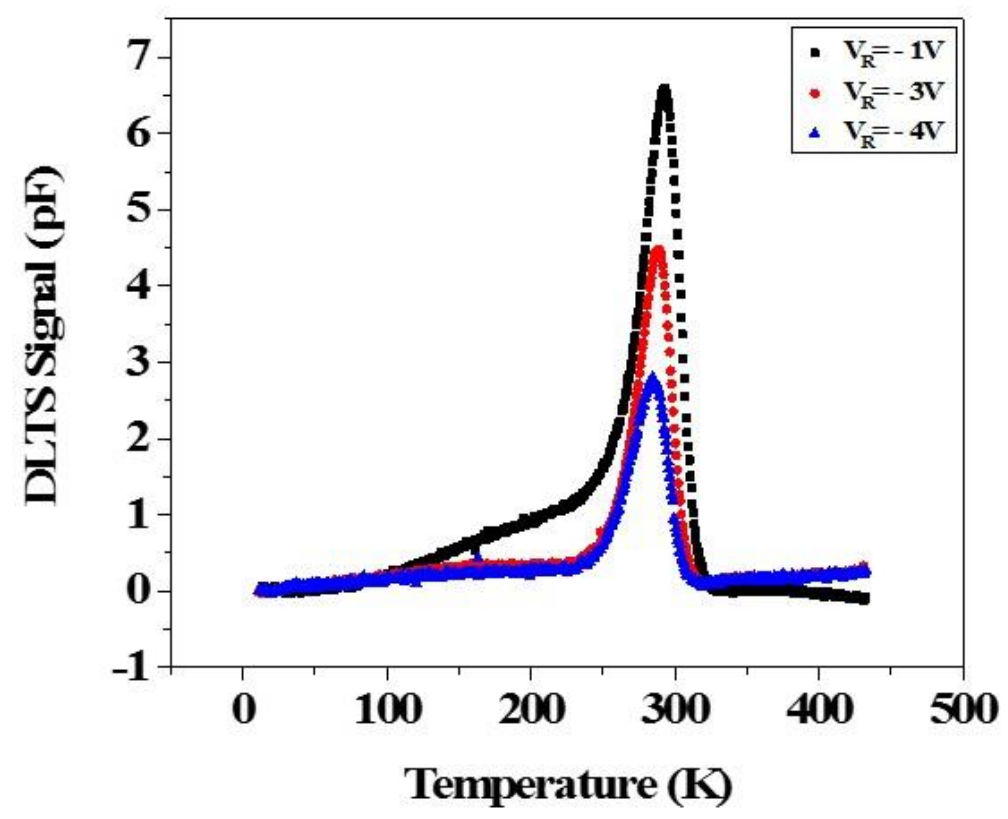

Fig. 12 DLTS signal for PLD sample at VR $=-1,-3$, and $-4 \mathrm{~V}$ 

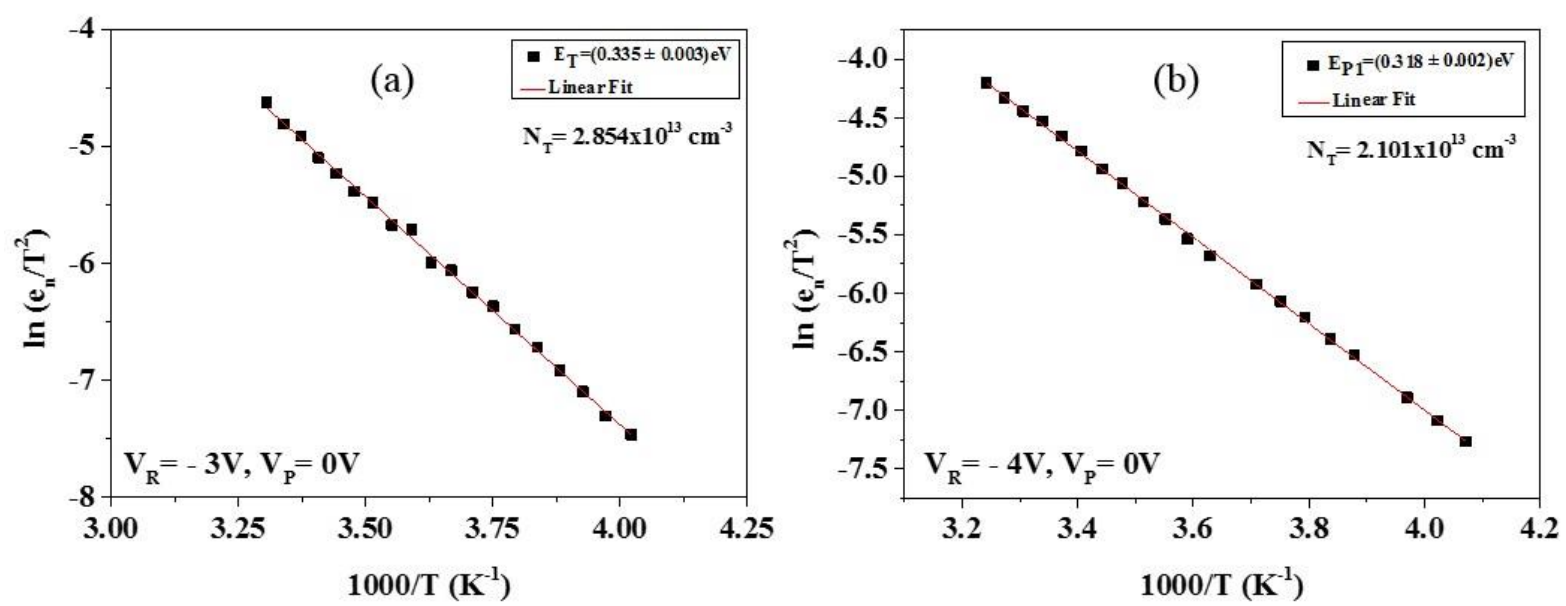

Fig. 13 Arrhenius plots for PLD sample obtained from Laplace DLTS at (a) $V_{R}=-3 V$ and (b) $V_{R}=-4$ V.

\section{Conclusion}

The effect of the growth technique on the structural, electrically and optically active defects in In-doped $\mathrm{TiO}_{2}$ has been investigated using two $\mathrm{TiO}_{2}$ sample sets prepared by PLD and sputtering techniques. The samples grown by sputtering technique have shown more defects than those grown by PLD. This could be related to the coexistence of both anatase and rutile phases present in the thin film deposited by sputtering. As a consequence, the I-V characteristics show lower reverse current for PLD sample as compared with the sputtering sample. PLD sample has a better value of ideality factor than sputtering sample. One defect has been found in PLD sample set where five defects have been detected in the sputtering sample set. Due to the lower leakage currents and less number of defects in PLD sample, it is concluded that the PLD technique is better suited for the growth of In-doped $\mathrm{TiO}_{2}$.

\section{Acknowledgements}

The author would like to thank Qassim University, Saudi Arabia, for funding his $\mathrm{PhD}$ studies. The authors also acknowledge the financial supports from the Brazilian agencies (Fundação de Amparo a Pesquisa do Estado de São Paulo (FAPESP grants 2016/10668-7 and 
2014/50513-7) and Conselho Nacional de Desenvolvimento Científico e Tecnológico (CNPq) (grant 3181/2014-1) and (FAPDF)17077.78.35088.2504/2017. 


\section{References}

1. Stadler, A., Transparent conducting oxides-An up-to-date overview. Materials, 2012. 5(4): p. 661-683.

2. Hashimoto, K., H. Irie, and A. Fujishima, TiO2 photocatalysis: a historical overview and future prospects. Japanese journal of applied physics, 2005. 44(12R): p. 8269.

3. Sarkar, M.B., et al., Enlarged broad band photodetection using Indium doped TiO2 alloy thin film. Journal of Alloys and Compounds, 2014. 615: p. 440-445.

4. Chinnamuthu, P., et al., Band gap enhancement of glancing angle deposited TiO2 nanowire array. Journal of Applied Physics, 2012. 112(5): p. 054315.

5. Amtout, A. and R. Leonelli, Optical properties of rutile near its fundamental band gap. Physical Review B, 1995. 51(11): p. 6842.

6. Tang, H., et al., Urbach tail of anatase TiO 2. Physical Review B, 1995. 52(11): p. 7771.

7. Wang, E., W. Yang, and Y. Cao, Unique surface chemical species on indium doped TiO2 and their effect on the visible light photocatalytic activity. The Journal of Physical Chemistry C, 2009. 113(49): p. 20912-20917.

8. Al Saqri, N.A., et al., Investigation of defects in indium doped TiO 2 thin films using electrical and optical techniques. Journal of Alloys and Compounds, 2017. 698: p. 883-891.

9. Nowotny, J., T. Bak, and M.A. Alim, Dual mechanism of indium incorporation into TiO2 (Rutile). The Journal of Physical Chemistry C, 2014. 119(2): p. 1146-1154.

10. Morgan, B.J. and G.W. Watson, Polaronic trapping of electrons and holes by native defects in anatase TiO 2. Physical Review B, 2009. 80(23): p. 233102.

11. Huang, H.-H., et al., Preparation of rutile and anatase phases titanium oxide film by $R F$ sputtering. Journal of nanoscience and nanotechnology, 2008. 8(5): p. 26592664.

12. Mikami, M., et al., Lattice dynamics and dielectric properties of TiO 2 anatase: a first-principles study. Physical Review B, 2002. 66(15): p. 155213.

13. Lukačević, I., et al., Lattice dynamics and Raman spectrum of rutile TiO2: The role of soft phonon modes in pressure induced phase transition. Materials Chemistry and Physics, 2012. 137(1): p. 282-289.

14. Sze, S.M. and M.K. Lee, Semiconductor devices : physics and technology. 2013, Singapore: Wiley.

15. Pillai, P., et al., Extraction of Schottky barrier at the F-doped SnO2/TiO2 interface in Dye Sensitized solar cells. Journal of Renewable and Sustainable Energy, 2014. 6(1): p. 013142.

16. Werner, J.H., Schottky barrier and pn-junctionI/V plots-Small signal evaluation. Applied Physics A: Materials Science \& Processing, 1988. 47(3): p. 291-300.

17. Van, C.N. and K. Potje-Kamloth, Electrical and NO $x$ gas sensing properties of metallophthalocyanine-doped polypyrrole/silicon heterojunctions. Thin Solid Films, 2001. 392(1): p. 113-121.

18. Jameel, D., et al., Electrical performance of conducting polymer (SPAN) grown on GaAs with different substrate orientations. Applied Surface Science, 2016. 387: p. 228-236.

19. Aydoğan, Ş., M. Sağlam, and A. Türüt, On the barrier inhomogeneities of polyaniline/p-Si/Al structure at low temperature. Applied surface science, 2005. 250(1): p. 43-49.

20. Aziz, M., et al., Electrical Behavior of MBE Grown Interfacial Misfit GaSb/GaAs Heterostructures With and Without Te-Doped Interfaces. IEEE Transactions on Electron Devices, 2015. 62(12): p. 3980-3986.

21. Tripathi, S. and M. Sharma, Analysis of the forward and reverse bias IV and CV characteristics on Al/PVA: n-PbSe polymer nanocomposites Schottky diode. Journal of Applied Physics, 2012. 111(7): p. 074513. 
22. Korucu, D., A. Turut, and H. Efeoglu, Temperature dependent I-V characteristics of an Au/n-GaAs Schottky diode analyzed using Tung's model. Physica B: Condensed Matter, 2013. 414: p. 35-41.

23. Al Saqri, N., et al., Investigation of the effects of gamma radiation on the electrical properties of dilute GaAs $1-x N$ x layers grown by Molecular Beam Epitaxy. Current Applied Physics, 2015. 15(10): p. 1230-1237.

24. Miyagi, T., et al., Photocatalytic property and deep levels of $\mathrm{Nb}$-doped anatase TiO2 film grown by metalorganic chemical vapor depostion. Japanese journal of applied physics, 2004. 43(2R): p. 775.

25. Pallotti, D.K., et al., Photoluminescence Mechanisms in Anatase and Rutile TiO2. The Journal of Physical Chemistry C, 2017. 121(16): p. 9011-9021.

26. Skowronski, L., R. Szczesny, and K. Zdunek, Optical and microstructural characterization of amorphous-like Al 2 O 3, SnO 2 and TiO 2 thin layers deposited using a pulse gas injection magnetron sputtering technique. Thin Solid Films, 2017. 632: p. 112-118.

27. Iijima, K., et al., Influence of oxygen vacancies on optical properties of anatase TiO 2 thin films. Journal of Luminescence, 2008. 128(5): p. 911-913.

28. Yang, Y., et al., Visible and near-infrared electroluminescence from $\mathrm{TiO} / \mathrm{p}+-\mathrm{Si}$ heterostructured device. AIP Advances, 2014. 4(4): p. 047109.

29. Kim, H.S., et al., High performance solution-processed indium oxide thin-film transistors. Journal of the American Chemical Society, 2008. 130(38): p. 1258012581.

30. Chan, C.-H., et al., Optical characterization of structural quality in the formation of In2O3 thin-film nanostructures. The Journal of Physical Chemistry C, 2016. 120(38): p. 21983-21989.

31. Meléndez, J.J. and M. Wierzbowska, In2O3 doped with hydrogen: electronic structure and optical properties from the pseudopotential Self-Interaction Corrected Density Functional Theory and the Random Phase Approximation. The Journal of Physical Chemistry C, 2016. 120(7): p. 4007-4015.

32. Ghosh, A., et al., Detailed investigation of defect states in Erbium doped In2O3 thin films. Materials Research Bulletin, 2018. 99: p. 211-218.

33. Johannsen, S.R., et al., Influence of TiO 2 host crystallinity on Er 3+ light emission. Optical Materials Express, 2016. 6(5): p. 1664-1678.

34. Krustok, J., H. Collan, and K. Hjelt, Does the low-temperature Arrhenius plot of the photoluminescence intensity in CdTe point towards an erroneous activation energy? Journal of applied physics, 1997. 81(3): p. 1442-1445.

35. Wang, X., et al., Trap states and carrier dynamics of TiO 2 studied by photoluminescence spectroscopy under weak excitation condition. Physical Chemistry Chemical Physics, 2010. 12(26): p. 7083-7090.

36. Lang, D., Deep-level transient spectroscopy: A new method to characterize traps in semiconductors. Journal of applied physics, 1974. 45(7): p. 3023-3032.

37. Dobaczewski, L., A. Peaker, and K. Bonde Nielsen, Laplace-transform deep-level spectroscopy: The technique and its applications to the study of point defects in semiconductors. Journal of Applied Physics, 2004. 96(9): p. 4689-4728.

38. Salama, A. and L. Cheng, The Effects of Titanium Impurities in N+/P Silicon Solar Cells. Journal of The Electrochemical Society, 1980. 127(5): p. 1164-1167. 